\title{
Necrosis of the pancreas in the haemolytic uraemic syndrome
}

\author{
RA PRIMHAK, LS TAITZ, S VARIEND, DHK WEBB, A CSER \\ From the Department of Paediatrics, University of Sheffield, Children's Hospital, Sheffield
}

SUMMARY A case of haemolytic uraemic syndrome in a three year old boy is described. The clinical course was complicated by hyperglycaemia, and biochemical assay of plasma showed an almost total lack of pancreatic insulin. Extensive necrosis of the exocrine and endocrine pancreas was found at necropsy. The possible pathological physiology of this complication and its prognostic importance are discussed.

The haemolytic uraemic syndrome is a multi-system disease. Small vessel necrosis has been found in most organs, including the islet cells of the pancreas. ${ }^{1-3}$ Recently, Upadhaya et al described three patients who developed severe hyperglycaemia during haemolytic uraemic syndrome following diazoxide administration. ${ }^{4}$ We describe a case of haemolytic uraemic syndrome in a patient who did not receive diazoxide but who developed severe hyperglycaemia associated with extensive destruction of pancreatic tissue.

\section{Case report}

A 3 year old boy was admitted to hospital with an eight day history of diarrhoea and vomiting, with three days of bloody stools, and a five day history of abdominal pain. He had been treated with a standard glucose and electrolyte solution. On admission he was anuric, and prerenal failure was diagnosed. He was treated with volume expansion and, subsequently, antibiotics following bacteriological culture of blood, stool, and urine (all negative). He remained anuric and was transferred to Sheffield Children's Hospital for further management of his renal failure. Examination showed an alert, orientated boy who was mildly oedematous. His blood pressure was $130 / 90 \mathrm{~mm} \mathrm{Hg}$ and a grade $1 / 6$ systolic ejection murmur was audible at the left sternal edge. His abdomen was distended but not tender and contained free fluid. No masses were palpable, and the bowel sounds were reduced. Rectal examination was unremarkable. The remainder of the examination was normal.

Accepted for publication 15 February 1984
Results of laboratory investigations were as follows: blood urea $23 \mathrm{mmol} / \mathrm{l}$; serum sodium $126 \mathrm{mmol} / \mathrm{l}$, potassium $3.6 \mathrm{mmol} / \mathrm{l}$, creatinine $490 \mu \mathrm{mol} / \mathrm{l}$; haemoglobin $10 \mathrm{~g} / \mathrm{dl}$; white cell count $36 \times 10^{9} / 1$ (80\% neutrophils); platelets $17 \times 10^{9} / 1$. The blood film contained fragmented cells. Haemolytic uraemic syndrome was diagnosed. Clotting studies showed raised concentrations of fibrin degradation products $(96 \mu \mathrm{g} / \mathrm{ml})$ and a prothrombin time of $22.5 \mathrm{~s}$ (control $13 \mathrm{~s}$ ). Thrombin time and KCCT were normal. Serum aspartate transaminase concentration was $215 \mathrm{IU} / \mathrm{l}$ and alanine transaminase $158 \mathrm{IU} / \mathrm{l}$. Serum amylase concentration was 689 IU/l (normal 100-400 IU/l) on admission, and fell thereafter to within the normal range.

Originally he was managed using a conservative regimen for acute renal failure. Five hours after admission he suffered a generalised convulsion with left sided predominance; his condition gradually deteriorated with clouding of consciousness and multiple seizures, which were treated with paraldehyde and phenobarbitone. Peritoneal dialysis was started on the day after admission. Ascitic fluid obtained at the insertion of the dialysis catheter contained $130 \times 10^{6}$ white cells/l (70\% neutrophils), $20 \mathrm{~g} / 1$ protein, and was sterile.

Three days after admission the child suffered a cardiorespiratory arrest and spontaneous cardiac output was restored only after $45 \mathrm{~min}$ of resuscitation, which included dopamine and adrenaline. Severe hyperglycaemia developed, the blood glucose concentration reaching a peak of $67.5 \mathrm{mmol} / \mathrm{l}$. This did not resolve spontaneously, and was eventually managed with a low dose insulin infusion.

After resuscitation there was no return of normal cerebral function, with absent brain stem reflexes, and three days later ventilation was discontinued. 


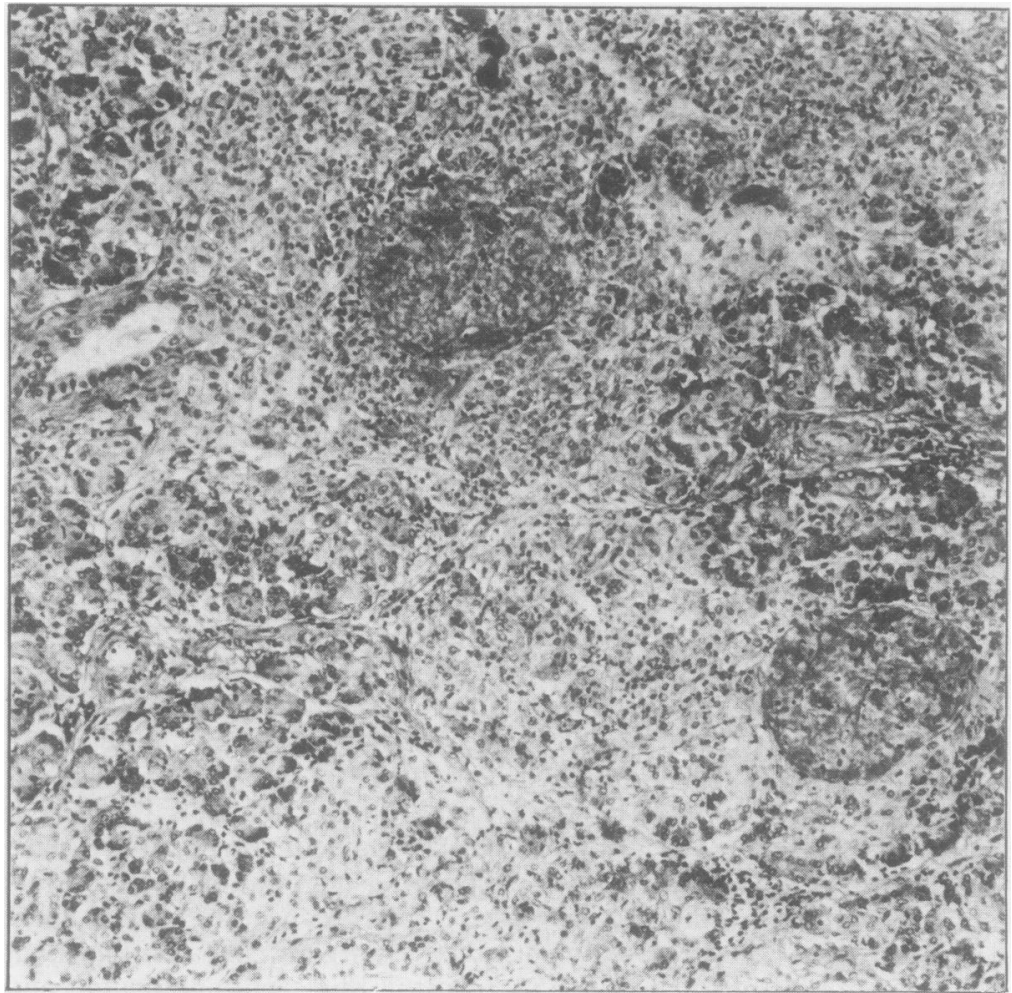

Fig. 1 Extensive necrosis of exocrine pancreas with conspicuous polymorph infiltration. Two rounded structures with heavy fibrin deposition and devoid of cellular detail probably represent necrosed islets. A vessel containing a fibrin thrombus is included in the upper part of the field. Martius scarlet blue. Original magnification $\times$ 130.

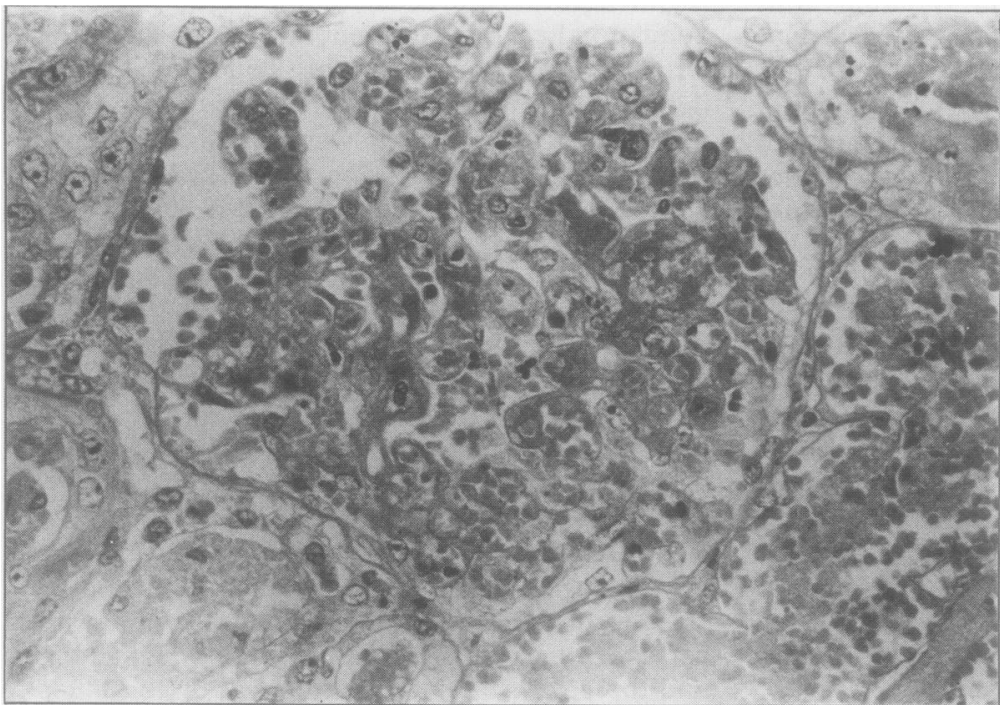

Fig. 2 Glomerulus with dilated capillaries containing pooled red blood cells and fibrin deposition. Capillary walls are thickened in places. Free red blood cells are seen in the urinary spaces. Martius scarlet blue. Original magnification $\times 526$. 


\section{PATHOLOGY}

Postmortem examination was carried out within $2 \mathrm{~h}$ of death. Apart from considerable cerebral oedema and a focus of transverse myelitis, the main pathological changes were found in the kidneys and pancreas. The pancreas showed gross and microscopical evidence of large confluent areas of coagulative necrosis affecting the whole organ. Necrotic areas were heavily infiltrated by polymorphonuclear leucocytes. Only narrow zones of exocrine tissue persisted along the lobular peripheries and periarteriolar areas. Wholly or partially necrotic islets were frequently outlined by erythrocyte pooling and fibrin deposition (Fig. 1). Many arterioles were occluded by fibrin thrombi, and fibrinoid necrosis of arteriolar walls, occasionally infiltrated and surrounded by polymorphs, were also present. The latter feature suggested associated arteritis.

There was bilateral renal cortical necrosis. The better preserved juxtamedullary glomeruli in particular showed pronounced erythrocyte clumping and fibrin deposition, which occluded or lined capillary lumina (Fig. 2). Capillary walls were thickened and vacuolated in places. Fibrin was also present within the lumina of some afferent arterioles. Extensive virological studies on necropsy material were negative.

\section{INSULIN STUDIES}

Plasma insulin concentration measured by radioimmunoassay during severe hyperglycaemia, before insulin infusion, was $3 \mathrm{mU} / 1$. Pancreatic tissue was frozen after necropsy and kept at $-80^{\circ} \mathrm{C}$ until assay. Samples were taken from four different parts of the pancreas and weighed 39-115 mg wet tissue. They were homogenised in $205 \mathrm{ml}$ acid ethanol and extracted overnight at $4^{\circ} \mathrm{C}$, then sonicated in $500 \mu \mathrm{l}$ aliquots, centrifuged, and assayed for insulin by radioimmunoassay. In three samples, insulin was not detectable; the fourth contained $0.362 \mathrm{nmol} / \mathrm{g}$ of tissue. This is about $1 \%$ of the normal pancreatic insulin concentration in infancy. ${ }^{5}$

\section{Discussion}

Pancreatic small vessel involvement in haemolytic uraemic syndrome is now well recognised. ${ }^{24} \mathrm{~A}$ patient similar to ours with haemolytic uraemic syndrome and severe hyperglycaemia was described by Burns $e^{t} \mathrm{al}^{3}$ and, at necropsy, almost complete destruction of the islet tissue was found. Adelman et al ${ }^{6}$ described a case of mild haemolytic uraemic syndrome associated with insulin dependent diabetes mellitus. Three further patients who had severe hyperglycaemia during the course of haemolytic uraemic syndrome were described by Andreoli and
Bergstein, ${ }^{7}$ but all lıăd received diazoxide before the development of hyperglycaemia. They documented low serum insulin concentrations in two patients studied, but in the one, in whom histology of the pancreas was available, the islets were preserved. One survivor remains an insulin dependent diabetic. Although our patient did not receive hyperglycaemic drugs but did undergo peritoneal dialysis with hypertonic glucose for short periods, which may occasionally cause hyperglycaemia, we found only a minimal insulin response to his extreme hyperglycaemia and a virtual absence of insulin from the pancreas, consistent with the extensive necrosis present. The absence of further rise in amylase concentration after the first value was presumably a reflection of the extent of the damage and poses diagnostic difficulties in such cases. Nevertheless, clinical and biochemical features suggesting pancreatic involvement were present on admission.

Microscopical examination of the pancreas showed extensive necrosis with severe involvement of exocrine and islet tissue. The precise cause of the pancreatic necrosis is difficult to ascertain. The episode of cardiorespiratory arrest with associated organ ischaemia may have been partly, or wholly, responsible, but pancreatic necrosis following recovery from cardiac arrest is not known to occur. Apart from renal cortical necrosis, which may accompany haemolytic uraemic syndrome and which is considered to be due to local mechanisms, ${ }^{9}$ there was no other evidence to suggest appreciable tissue ischaemia. Several arterioles in the pancreas also showed features reminiscent of arteritis. An arteritic lesion of the pancreas was referred to by Lieberman et $a l^{2}$ and, while small vessel thrombosis with infarction is the most likely explanation, an associated immunological process cannot be excluded. An immunological mechanism in the pathogenesis of haemolytic uraemic syndrome has been postulated. ${ }^{8}$

Despite improved survival rates for haemolytic uraemic syndrome, some cases still prove fatal, particularly when there is appreciable central nervous system involvement. ${ }^{9}$ Of the six patients with haemolytic uraemic syndrome and hyperglycaemia described so far five have had severe illness with anuria and coma and three have died. This suggests that hyperglycaemia secondary to pancreatic islet destruction is an adverse prognostic feature in haemolytic uraemic syndrome. The extensive pancreatic necrosis described here is probably an extreme form of this complication.

This paper was prepared with support from the CHRIS fund of the Children's Hospital, Sheffield. 


\section{References}

' Giautonio CA, Vitacco M, Mendilaharzu F, Gallo GE, Sojo ET. The hemolytic uremic syndrome. Nephron 1973;11:174-92.

${ }^{2}$ Lieberman E, Heuser E, Donnell GN, Landio BH, Hammond GD. Hemolytic-uremic syndrome: clinical and pathological considerations. $N$ Engl J Med 1966;275:227-36.

${ }^{3}$ Burns JC, Breman ER, Fagre JL, Shikes RH, Lum GM. Pancreatic islet cell necrosis: association with hemolytic uremic syndrome. J Pediatr 1982;100:582-4.

${ }^{4}$ Upadhaya K, Barwick K, Fishaut M, Kashganan M, Siegal NJ. The importance of non renal involvement in hemolytic uremic syndrome. Pediatrics 1980;65:115-20.

s Polak JM, Bloom SR. In: Andreani D, Lefebvre PJ, Marks V, eds. Current views of hypoglycaemia and glucagon. New York: Academic Press, 1980:367-78.

- Adelman RD, Halsted CC, Sheikholishlam BM. Hemolytic uremic syndrome: associated conditions. $J$ Pediatr 1980;97:161.

${ }^{7}$ Andreoli SP, Bergstein JM. Development of insulin dependent diabetes mellitus during the hemolytic uremic syndrome. $J$ Pediatr 1982;100:541-5.

${ }^{8}$ Katz J, Lurie A, Kaplan BS, Krawitz S, Metz J. Coagulation findings in the haemolytic-uraemic syndrome of infancy: similarity to hyperacute renal allograft rejection. $J$ Pediatr 1971;78:426-34.

9 Gianantonio C, Vitacco M, Mendilaharzu F, Rutty A, Mendilaharzu J. The hemolytic uremic syndrome. $J$ Pediatr 1964;64:478-9.

Requests for reprints to: Dr LS Taitz, Department of Paediatrics, Children's Hospital, Western Bank, Sheffield S10 2TH, England. 